\title{
PROVAS DE CIÊNCIAS DA NATUREZA DA UNICAMP CONTRIBUEM PARA MUDANÇAS NO ENSINO DE CIÊNCIAS? UMA ANÁLISE DO VESTIBULAR 2019
}

\author{
Rodrigo Bastos Cunha ${ }^{1}$ \\ http://orcid.org/0000-0003-3679-1062
}

RESUMO: Embora as pesquisas sobre ensino de ciências focadas nas relações entre ciência, tecnologia e sociedade já estejam bastante consolidadas e tenham contribuído para concepções de ensino voltadas para a cidadania e a tomada de decisão, sabe-se que o ensino nas escolas básicas é fortemente pautado pelo que cobram os exames de acesso ao ensino superior, como o Enem e os vestibulares. O objetivo deste artigo é analisar o quanto as provas de ciências da natureza do vestibular da Unicamp incorporam os pressupostos do ensino CTS que aparecem nos currículos de ciências da natureza e, consequentemente, sua influência em mudanças no ensino de ciências. Trata-se de uma análise qualitativa do vestibular 2019 sob a ótica da relação entre letramento científico e ensino CTS estabelecida por pesquisadores do ensino de ciências. O resultado da análise mostra que, em geral, o que é cobrado nessas provas não envolve participação ativa em tomada de decisão.

PALAVRAS-CHAVE: ensino CTS, letramento científico, vestibular

\section{DO UNICAMP'S TESTS OF NATURAL SCIENCES CONTRIBUTE TO CHANGES IN SCIENCE TEACHING? AN ANALYSIS OF THE 2019 ENTRANCE EXAM}

\begin{abstract}
Although research on science teaching focused on the relationship between science, technology and society is already well consolidated and has contributed to teaching concepts aiming for citizenship and decision making, it is known that teaching in basic education schools is strongly guided by what higher education access exams such as Enem and entrance exams assess. The aim of this paper is to analyze how much the tests of natural sciences in the Unicamp entrance exam incorporate the assumptions of STS teaching that appear in the natural sciences curricula and, consequently, their influence on changes in science teaching. This is a qualitative analysis of the 2019 entrance exam from the perspective of the relationship between scientific literacy and STS teaching established by researchers in science teaching. The result of the analysis shows that, in general, what is assessed in these tests does not involve active participation in decision making.
\end{abstract}

KEYWORDS: STS teaching, scientific literacy, entrance exam

1 Doutor em Linguística Aplicada, pesquisador e docente do Programa de Pós-graduação em Divulgação Científica e Cultural da Universidade Estadual de Campinas, Campinas, São Paulo, Brasil, rbcunha@unicamp.br 


\section{¿LAS PRUEBAS DE LAS CIENCIAS NATURALES DE UNICAMP CONTRIBUYEN A LOS CAMBIOS EN LA ENSEÑANZA DE LAS CIENCIAS? ANÁLISIS DEL EXAMEN DE INGRESSO 2019}

RESUMEN: Aunque la investigación sobre la enseñanza de las ciencias centrada en la relación entre ciencia, tecnología y sociedad ya está bastante consolidada y ha contribuido para concepciones de enseñanza orientadas a la ciudadanía y la toma de decisiones, se sabe que la enseñanza en las escuelas de la educación básica está fuertemente orientada por lo que evalúan los exámenes de acceso a la educación superior, como Enem y los exámenes de ingreso. El objetivo de este trabajo es analizar en qué medida las pruebas de ciencias naturales del examen de ingreso a la Unicamp incorporan los presupuestos de la enseñanza CTS que aparecen en los currículos de ciencias de la naturaleza y, en consecuencia, su influencia en los cambios en la enseñanza de las ciencias. Este es un análisis cualitativo del examen de ingreso de 2019 desde la perspectiva de la relación entre la alfabetización científica y la enseñanza CTS establecida por investigadores en enseñanza de las ciencias. El resultado del análisis muestra que, en general, lo que se evalúa en estas pruebas no implica una participación activa en la toma de decisiones.

PALABRAS CLAVE: enseñanza CTS, alfabetización científica, examen de ingreso.

\section{Introdução}

Após a Segunda Guerra Mundial, com a imagem da ciência abalada pela calamidade causada pela bomba atômica, a comunidade científica ligada ao ensino de ciências nos Estados Unidos começou a discutir a necessidade de se promover o letramento científico da população. Um dos objetivos era capacitar os estudantes para competir em uma sociedade cada vez mais desenvolvida em ciência e tecnologia; outro era obter o apoio do público para o financiamento das pesquisas no contexto da corrida espacial com a então União Soviética (HURD, 1958). Nas décadas seguintes, surgiriam diferentes interpretações do conceito de letramento científico e de quais seriam seus objetivos (ROBERTS, 1983).

Com os avanços dos estudos sobre os impactos ambientais do desenvolvimento científico e tecnológico e, sobretudo, após a realização da primeira conferência mundial sobre meio ambiente, organizada pelas Nações Unidas em Estocolmo, em 1972, ganha força em todo o mundo o movimento Ciência-Tecnologia-Sociedade (CTS). A partir das pesquisas ligadas a esse movimento, surgem várias propostas de mudanças no ensino de ciências, para que ele se torne mais significativo para os estudantes, com foco em uma formação voltada 
para a tomada de decisões na vida cotidiana como consumidores e cidadãos. Isso se refletiria, na análise de Roberts (2007), em duas visões distintas de letramento científico ligadas a uma tensão ideológica que sempre foi inerente ao ensino de ciências: uma com foco na natureza da ciência, seus processos e produtos e outra com foco em temas sociais com algum componente científico ou tecnológico que os estudantes provavelmente encontrarão em suas vidas.

No Brasil, já é bastante robusta a contribuição das pesquisas de pós-graduação sobre letramento científico e sobre ensino CTS (CUNHA, 2019; RODRIGUES \& QUADROS, 2019; SOUSA et al, 2019), que abordam, entre outras coisas, a formação de professores e a discussão em sala de aula sobre temas sociais com algum componente científico ou tecnológico, seja através do uso de materiais didáticos inovadores ou do aproveitamento pedagógico de textos de divulgação científica.

Entretanto, as iniciativas de incorporação das propostas de mudanças no ensino de ciências sugeridas nos estudos nacionais e internacionais, tanto nos cursos de formação de professores de ciências quanto em materiais didáticos mais voltados para a realidade dos estudantes, são insuficientes para que elas se concretizem nas salas de aula da educação básica. As aulas de ciências da natureza no ensino médio são predominantemente pautadas pelo que é cobrado nos processos seletivos para acesso ao ensino superior. Portanto, é preciso que provas como o Exame Nacional do Ensino Médio (Enem) e os vestibulares também incorporem as mudanças sugeridas pelas pesquisas, as quais já aparecem a pelo menos duas décadas nos Parâmetros Curriculares Nacionais do Ensino Médio (BRASIL, 2000)².

O objetivo deste artigo é fazer uma análise qualitativa das provas comentadas pelas bancas de biologia, física e química da 1a fase do vestibular da Universidade Estadual de Campinas (Unicamp) de 2019, sob a ótica da relação entre letramento científico e ensino CTS estabelecida por pesquisadores do ensino de ciências, para verificar o quanto essas provas incorporam as premissas do movimento CTS e, consequentemente, em que medida contribuem para que as mudanças sugeridas pelas pesquisas nessa área sejam de fato implementadas no ensino de ciências.

2 No dia 2 de abril de 2018, o Ministério da Educação apresentou ao Conselho Nacional de Educação a 3ạ versão da Base Nacional Comum Curricular, em substituição aos Parâmetros Curriculares. O documento está disponível em http://basenacionalcomum.mec.gov.br/images/BNCC_EI_EF_110518_versaofinal_site. pdf, mas não possui ficha catalográfica com as informações requeridas para citação bibliográfica pelas normas da ABNT. 


\title{
Ensino CTS e letramento científico
}

Rodrigues (2010) observa que pesquisas em filosofia e sociologia da ciência originaram o movimento CTS, o qual, entre outras coisas, tentava desconstruir a visão de que a ciência seria neutra. Com isso, segundo ela, "em meados da década de 1960 e início da de 1970 surge um olhar mais crítico sobre o papel da ciência e da tecnologia na sociedade, o que trouxe desdobramentos para o ensino de ciências" (RODRIGUES, 2010, p. 16). Rodrigues (2010, pp. 21-22) considera que o movimento CTS pode ser um referencial para mudanças na educação científica, "por apresentar uma visão de educação básica voltada para cidadania", com foco "em torno de temas sociais e não somente nos conceitos científicos".

Santos (2002, p. 35) aponta que "o letramento em ciência e tecnologia, LCT, tem sido associado a estudos de compreensão pública da ciência, ciência para todos e educação em ciência-tecnologia-sociedade, CTS". De acordo com ele,

\begin{abstract}
o letramento científico e tecnológico tornou-se um lema do ensino de ciências, em contraste ao lema cientificista das décadas de cinquenta e sessenta, do século passado, que era centrado na preparação dos jovens para agirem na sociedade como cientistas ou optarem pela carreira científica. Nesse novo contexto, o letramento científico objetiva levar os alunos a compreenderem como a ciência e a tecnologia influenciam-se mutuamente; a tornarem-se capazes de usar o conhecimento científico e tecnológico na solução de seus problemas no dia-a-dia; e a tomarem decisões com responsabilidade social. Para o alcance desses objetivos, é fundamental a adoção de temas envolvendo questões sociais relativas à ciência e tecnologia que estejam diretamente vinculadas à vida dos alunos (SANTOS, 2002, p. 28).
\end{abstract}

Refletindo sobre essas observações de Santos (2002), duas questões importantes precisam ser consideradas. Como lembra Roberts (2007, p. 752), "a educação em ciência tem que resolver de alguma forma os problemas associados com o ensino de dois grupos de estudantes muito diferentes", os que vão seguir carreira científica e todos os demais. Isso significa que o ensino de ciências, além de oferecer uma base para que uma parcela dos estudantes possa dar continuidade, no ensino superior, a suas aspirações científicas, deve preocupar-se com o conhecimento que seria significativo para todos e não apenas para os futuros cientistas. Outra questão importante é a ideia de usar 
conhecimento para a solução de problemas cotidianos e a tomada de decisões com responsabilidade social. Não se trata de exemplos de problemas encontrados pela humanidade e solucionados pela ciência, como é comum de se ver no ensino tradicional ou nos exames de avaliação. Trata-se de decisões comuns que os estudantes terão que tomar ao longo de suas vidas como consumidores e cidadãos, como, por exemplo, qual produto consumir ou não consumir, que política pública apoiar ou não apoiar.

\section{A influência dos exames de acesso à universidade nas aulas do ensino médio}

Entre as contribuições das pesquisas sobre ensino CTS incorporadas pelos Parâmetros Curriculares Nacionais do Ensino Médio (BRASIL, 2000), está o incentivo à interdisciplinaridade e à contextualização do conhecimento a ser ensinado. Moeto, Pereira e Menezes (2017, p. 2) observam que "o vestibular ainda é o principal orientador dos conteúdos ministrados nas disciplinas do ensino médio. Isso se deve a grande importância que as escolas, sejam elas públicas ou privadas, agregam aos exames de seleção". Ao analisar provas de física em vestibulares, eles afirmam que "mesmo que contextualizadas, o que se vê, em geral, são questões que requerem a simples memorização de um conceito" (MOETO; PEREIRA; MENEZES, 2017, p. 7). Em função disso, esses autores questionam: "O modelo atual dos processos seletivos, incluindo aqui o exame do Enem, não ajuda a perpetuar os modelos curriculares tradicionais, dificultando mudanças mais efetivas no ensino de física?" (MOETO; PEREIRA; MENEZES, 2017, p. 7).

Gomes e Macedo (2007, p. 150) fazem esse mesmo tipo de reflexão sobre o ensino de química, que, segundo elas, "foi reduzido à transmissão de informações, definições e leis isoladas, sem qualquer relação com a vida do aluno, exigindo deste, quase sempre, a pura memorização". De acordo com elas, ao planejar aquilo que se pretende ensinar, os professores partem de conceitos e definições. Porém, no entendimento dessas autoras, o ponto de partida deveria ser a experiência do cotidiano do aluno. Para Gomes e Macedo (2007, p. 152),

[...] há uma grande divergência entre o ensino voltado para o vestibular e as propostas de ensino de Química no cotidiano, tendo em vista os tipos de questões apresentados nas provas dos concursos. Enquanto, por um lado, grupos de pesquisa procuram construir propostas de ensino que favoreçam uma aprendizagem significativa para os alunos, relacionando temas do seu cotidia- 
no ao processo de construção do conhecimento químico, os concursos vestibulares continuam prezando um conhecimento memorístico e ocasional. Desta forma, provavelmente aí esteja um dos maiores entraves do ensino de química em nosso país, pois a influência do vestibular sobre as ações docentes tem demonstrado resultados desastrosos para os alunos (GOMES; MACEDO, 2007, p. 152).

\section{Ensino CTS e as provas de ciências da natureza no vestibular Unicamp}

Uma das recomendações dos Parâmetros Curriculares Nacionais do Ensino Médio (BRASIL, 2000), decorrente de contribuições das pesquisas sobre ensino CTS, é a escolha de temas que possam ser abordados de forma interdisciplinar. Nas provas de biologia, química e física da 1 a fase do vestibular Unicamp 2019, 25\% das questões (3 de um total de 12 em cada prova) são interdisciplinares, de acordo com as bancas elaboradoras (COMVEST, 2019a, 2019b, 2019c) ${ }^{3}$. No entanto, essa "interdisciplinaridade" nem sempre envolve a mobilização de conhecimentos em mais de uma disciplina.

A questão 79 da prova de biologia, por exemplo, é apontada como "interdisciplinar" com língua portuguesa, e apresenta trecho de um texto sobre o Projeto Genoma, mas o conhecimento necessário para o acerto da questão envolve apenas a disciplina de língua portuguesa e requer a distinção entre metáfora, alegoria e analogia. Na questão 80 da prova de física, apontada como "interdisciplinar" com língua portuguesa, ocorre o inverso: o enunciado menciona o uso de noções da física em obras da literatura, como $O$ Pêndulo de Foucault, de Umberto Eco, porém, o que é cobrado na questão requer apenas conhecimento em física sobre a relação entre o período de um pêndulo simples e a massa do corpo suspenso.

A banca elaboradora da prova de química, na questão 82, escolhe aderir à interdisciplinaridade optando por apresentar um texto ${ }^{4}$ em inglês extraído

3 Os documentos acessados para esta análise são as provas comentadas pelas bancas elaboradoras, em que são apresentados o objetivo de cada questão, a resposta correta com comentários e o desempenho dos candidatos.

$4 \mathrm{O}$ texto "Touching thermal-paper receipts could extend BPA retention in the body", do qual se extraiu o trecho reproduzido na prova, foi escrito por uma bacharel em química, Deirdre Lockwood, e está disponível em https://cen.acs.org/articles/95/i35/Touching-thermal-paper-receipts-extend.html. Lockwood, aparentemente, não tem familiaridade com a construção do texto jornalístico, do contrário, saberia que o título de uma matéria é fundamental para atrair (ou repelir) um leitor e teria evitado o uso de sigla que não é imediatamente reconhecida pela maioria do público. Ao contrário de ONU, Fifa ou Unicamp, poucos leitores saberiam, de antemão, o que seria BPA. Em um veículo jornalístico, caso um repórter inexperiente use uma sigla como essa no título de uma matéria, o editor certamente a excluiria.

Rev. Fac. Educ. (Univ. do Estado de Mato Grosso), Vol. 35, Ano 20, № 1, p. 91-111, jan/jun, 2021. 
do site de notícias Chemical \& Engineering News, ligado à American Chemical Society, dos Estados Unidos. Embora os responsáveis pelo site se considerem "a fonte de notícias mais abrangente e autorizada do mundo sobre química e campos correlatos" ${ }^{5}$, as escolhas lexicais do seu texto de notícia tornam o alcance de público bastante limitado a pessoas especializadas na área. Seja em português, em inglês ou em qualquer outra língua, é possível abordar de maneira acessível ao público leigo uma pesquisa envolvendo universidades de Estocolmo, na Suécia, e Alberta, no Canadá, para monitorar em voluntários a concentração de uma substância tóxica, cuja contaminação se dá pelo manuseio de papel térmico como os que são usados em máquinas de pagamento por cartão. Não é preciso que todo leitor se torne um químico ou incorpore o vocabulário dessa área para que entenda a relevância social da investigação.

Em relação à interdisciplinaridade no ensino CTS, Schnetzler e Santos (1997) apontam o fogo como exemplo de tema que pode ser usado como ponto de partida para desencadear abordagens em diversas disciplinas. A partir dele, é possível tratar de combustão e combustíveis, exploração de recursos naturais, geopolítica, efeitos econômicos, sociais e ambientais do desenvolvimento científico e tecnológico desde a Revolução Industrial, mudanças climáticas e aquecimento global, entre outros temas pertinentes para todo e qualquer cidadão e não apenas o futuro cientista. De acordo com Schnetzler e Santos (1997, p. 82), o componente interdisciplinar de uma abordagem como essa é forte, "pois, ao enfocar aspectos sociais, necessariamente serão envolvidos conceitos e explicações das demais áreas das ciências naturais, bem como das ciências sociais (história, geografia, economia etc.)". Adiante, apontaremos uma rara questão que faz esse tipo de abordagem no vestibular Unicamp.

Além da interdisciplinaridade, os Parâmetros Curriculares Nacionais do Ensino Médio (BRASIL, 2000, p. 4) também afirmam buscar "dar significado ao conhecimento escolar, mediante a contextualização". De acordo com o documento oficial (BRASIL, 2000, p. 78), "o tratamento contextualizado do conhecimento é o recurso que a escola tem para retirar o aluno da condição de espectador passivo". A participação ativa é expressa nos Parâmetros Curriculares (BRASIL, 2000, p. 65) da seguinte forma: "empresas, sindicatos, associações de bairro, comunidades religiosas, cidadãos e cidadãs comuns começam a incorporar as políticas públicas, as decisões econômicas, as questões ambientais, como itens prioritários em suas agendas".

Essa ideia da participação ativa dos cidadãos nas tomadas de decisão é uma das contribuições das pesquisas sobre ensino CTS incorporadas pelos

5 De acordo com a página "About Us", disponível em https://cen.acs.org/static/about/aboutus.html. 
Parâmetros Curriculares. Segundo Schnetzler e Santos (1997, p. 67), "considerando o objetivo de formação do cidadão, pode-se destacar que os cursos que mais se enquadram em tal perspectiva são os que dão maior ênfase aos aspectos sociais da ciência e da tecnologia". De acordo com eles,

[...] o objetivo mais frequentemente apontado por inúmeros pesquisadores para os cursos com preocupação centrada na formação da cidadania refere-se ao desenvolvimento da capacidade de tomada de decisão ... Essa relaciona-se à solução de problemas da vida real que envolvem aspectos sociais, tecnológicos, econômicos e políticos, o que significa preparar o indivíduo para participar ativamente na sociedade democrática (SCHNETZLER; SANTOS, 1997, p. 68).

Na prova comentada de biologia (COMVEST, 2019a, p. 2), a banca elaboradora não fala explicitamente em contextualização, mas menciona a relação da biologia com a sociedade e "a presença de questões que abordam temas importantes para o país". Já na prova comentada de química (COMVEST, 2019b, p. 2), além da menção à abordagem de "temas atuais e familiares para a grande maioria dos candidatos", a banca elaboradora diz que buscou "contextualizar as questões, abordando os conteúdos a partir de situações reais da vida cotidiana". O mesmo é feito pela banca elaboradora na prova comentada de física (COMVEST, 2019c, p. 2), ao afirmar que "procurou-se contextualizar o conteúdo avaliado, fazendo referência a situações comuns da vida cotidiana ou a fatos científicos, alguns amplamente divulgados pela mídia".

Essa afirmação da banca de física dá uma pista de como ela interpreta a contextualização do conteúdo: não importa se o conhecimento que está sendo avaliado é ou vai ser usado em uma situação cotidiana da vida presente ou futura do estudante, contanto que o enunciado faça referência a algo da vida cotidiana.

Na questão 58 da prova de física, por exemplo, a pescaria, que pode fazer parte da vida alguns estudantes e não de outros, aparece apenas de maneira ilustrativa no enunciado. O conhecimento cobrado, sobre o módulo da tensão da linha que une a bóia ao anzol na vara de pescar, quando o peixe é fisgado, não vai ser usado por nenhum dos estudantes em uma situação real de pesca, tampouco como consumidores de peixes.

As questões 59, 60 e 61 dessa mesma prova têm um enunciado em comum que trata de drones usados para monitorar ambiente subaquático. Para o estudante que não vai trabalhar futuramente com física ou áreas afins, 
no entanto, o conhecimento cobrado em cada uma delas não vai ser usado em situações cotidianas envolvendo a participação ativa do cidadão e não é necessário sequer para entender uma reportagem na mídia sobre drones. Há alguma situação cotidiana em que alguém calcula a corrente elétrica fornecida pela bateria de um drone? Ou a pressão em uma determinada profundidade em que o drone mediu certa temperatura? Ou a transferência de calor em um cilindro parcialmente submerso? Até mesmo se considerarmos esse tipo de conhecimento apenas do ponto de vista cultural, temos que admitir que ele pode interessar a uns e não a outros. Porém, para a banca elaboradora, basta que o drone seja uma tecnologia presente no cotidiano para que se considere o conhecimento devidamente contextualizado.

A banca elaboradora da prova de química escolhe temas com potencial para discussões envolvendo cidadania e tomadas de decisão, mas esse potencial não é explorado de maneira adequada. A questão 83, por exemplo, apresenta uma pesquisa envolvendo humanos e aborda o risco de um erro técnico no cálculo da dose de cafeína a ser dada para os voluntários do estudo, 100 vezes maior que a planejada, que seria equivalente a três xícaras de café. Na prova comentada, a banca revela um dos seus objetivos nessa questão:

O uso de substâncias para aumentar o rendimento de atletas profissionais e amadores é bastante atual e há vários suplementos alimentares à disposição. Porém, deve-se ter muita cautela e evitar o uso indiscriminado dessas substâncias. Pelo exemplo, percebe-se que mesmo uma substância presente no cotidiano das pessoas pode oferecer riscos, a depender da dose ingerida (COMVEST, 2019b, p. 4).

Difícil estimar quantos dos milhares de candidatos fizeram a associação entre a cafeína do estudo e as substâncias usadas para aumentar o rendimento de atletas. Será que algum fez essa associação? Mesmo que se considere apenas o alerta para o risco da ingestão excessiva de cafeína, supor que algum estudante possa imaginar que, em uma situação cotidiana, alguém seja capaz de tomar 300 xícaras de café em um dia é algo fora da realidade.

$\mathrm{Na}$ questão 84, a banca sinaliza que vai tratar de um tema atual de extrema relevância, as fakes news. No entanto, a questão apresenta equivocadamente como exemplo de notícia falsa um artigo publicado na internet com um dado inconsistente. Há uma diferença enorme entre um texto descuidado na apuração das informações e um texto deliberadamente falso e mentiroso e é muito grave que os elaboradores de uma questão de vestibular não saibam 
distinguir entre uma coisa e outra. A banca justifica a escolha daquele artigo da internet da seguinte forma:

\begin{abstract}
O texto tinha como objetivo alertar aos leitores que não é o sal de cozinha o verdadeiro vilão da saúde, mas sim o glutamato monossódico. O texto, apesar de conscientizar as pessoas dos riscos da ingestão excessiva de sódio para a saúde humana, como para a hipertensão arterial, traz informações erradas sobre a quantidade de sódio que existem ${ }^{6}$ no glutamato monossódico. A questão tinha como objetivo levar os candidatos a fazerem uma reflexão sobre a validade das informações veiculadas na internet e, usando o conhecimento químico corretamente, corrigir parte do texto original (COMVEST, 2019b, p. 5).
\end{abstract}

Por melhores que sejam as intenções da banca elaboradora, nenhum cidadão, no seu cotidiano, vai realizar o cálculo da concentração de sódio no glutamato monossódico para checar se uma reportagem que está lendo contém um erro. O químico, que certamente faria isso, não escolhe como fonte de informação aquele site de onde se extraiu o artigo. Para que um cidadão saiba distinguir entre um texto cuidadoso e um descuidado (o que é muito diferente de um texto falso), é preciso que a escola básica trabalhe o letramento midiático.

Entre os itens que pesam na consistência de um texto jornalístico estão as fontes usadas para levantar as informações. A autora do artigo ${ }^{7}$ mencionado na questão de química não entrevistou ninguém e usou como fontes outros três sites da internet. Apenas um desses três aponta as pessoas envolvidas na produção de seu conteúdo: uma nutricionista e uma "health coach" que traduzem os treinamentos de um norte-americano chamado Tonny Robbins.

Algumas questões da prova de biologia também apresentam temas com potencial de discussão para tomadas de decisão como cidadão, cujo conhecimento cobrado, no entanto, não é o que vai ser usado futuramente pelo estudante para exercer sua cidadania. A questão 26, por exemplo, trata de um problema ambiental decorrente de uma atividade econômica, a produção de celulose. Porém, o conhecimento cobrado sobre a estrutura da parede celular de células vegetais não é necessário para entender uma reportagem sobre o tema na mídia ou para se posicionar diante de uma política pública sobre

6 Ao apontar o erro alheio, a banca elaboradora não se dá conta de que comete aqui um erro de concordância. 7 "Glutamato monossódico, o sabor que mata", escrito pela jornalista Thamyris Fernandes e publicado por Segredos do Mundo, do portal R7. Disponível em https://segredosdomundo.r7.com/glutamato-monossodico-o-sabor-que-mata/.

Rev. Fac. Educ. (Univ. do Estado de Mato Grosso), Vol. 35, Ano 20, № 1, p. 91-111, jan/jun, 2021. 
regulação de atividade econômica com impacto ambiental.

Da mesma forma, a questão 27 aborda um importante tema de saúde pública, a malária, mas cobra um conhecimento em parasitologia que o cidadão não precisa ter para entender uma reportagem sobre a pesquisa da Fiocruz no combate à malária ou se posicionar diante de políticas públicas envolvendo tanto questões sanitárias preventivas quanto o financiamento de pesquisas como a da Fiocruz para o tratamento da doença.

A seguir, apresentaremos a reprodução integral de uma questão da prova de biologia, uma questão da prova de química e uma questão da prova de física, como exemplos em que o conhecimento cobrado pelas bancas elaboradoras não envolve tomadas de decisão dos estudantes como consumidores e cidadãos. Em seguida, serão apresentadas duas questões em que a noção de cidadania aparece, de fato, no conhecimento que está sendo avaliado e nas quais há, efetivamente, interdisciplinaridade e contextualização do conhecimento a partir da realidade dos estudantes, e o enunciado não é uma mera ilustração daquilo que é cobrado.

\section{Questões em que o que é avaliado não envolve participação ativa como cidadão}

Imagem 1: questão 20 da prova de biologia da 1a fase do vestibular Unicamp 2019

Questăo 20

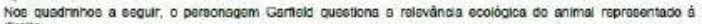

diresta.
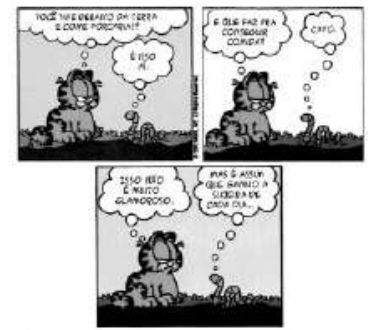

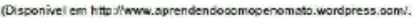

Assinale a aternativa que descreve corretamente aspectos andiogicos e ecologicos referentes a esac animal.

a) As minhocas sâo invertebrados do filo dos anelideos, possuem corpo celomado e segmentado. convertem detritos ingeridos em maléria crgênica e melhoram o arejamento do solo.

b) Ae cobrae-cegas săo vertebradoe do tlo dos anelideoe, pcesuem corpo paeudocalomado e reprocuçăo sexuods, sâo predadoras de pragas agricolas e meihoram o arcjamento do solo.

c) Aa cobraa-cagas sấo invertebradoe do nilo doe cordadoa, poesuem corpo calomado e nä́o segmentado a sẽo capazes de controler ervas daninhas, pos consomem suas raizes.

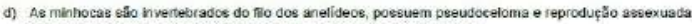
seáo predadoras de prages agricolas e meihoram o arejamento do solo

Fonte: Comvest (2019a)

A mera visualização da imagem de um dos personagens dos qua- 
drinhos acima não é suficiente para eliminar duas das quatro opções de respostas, pois a cobra-cega tem a aparência de uma grande minhoca. Um dos conhecimentos privilegiados no ensino de biologia e supostamente esperado na resolução dessa questão é a taxonomia. Se o estudante identificasse, pela imagem, que o animal é, ao mesmo tempo, invertebrado e anelídeo, eliminaria a possibilidade de ser uma cobra-cega, já que o item b diz que o animal é vertebrado e o item c diz que é cordado. A leitura do texto dos diálogos possibilita a dedução da resposta correta a partir da associação semântica de "detritos" com "porcarias" e "sujeira".

O objetivo aqui, no entanto, não é analisar se a questão é de fácil resolução ou não. Trata-se de questionar a relevância do conhecimento esperado pela banca avaliadora para quem não vai seguir carreira em biologia. Do ponto de vista cultural, pode ser interessante para alguns estudantes (e não para todos) saber que as minhocas "convertem detritos ingeridos em matéria orgânica e melhoram o arejamento do solo", ainda que esse conhecimento não vá ser usado em sua vida futura como consumidor e cidadão. Também seria interessante se essa informação específica do papel ecológico das minhocas fosse associada ao conhecimento tradicional (SCHIEDECK et al., 2010) e à agricultura familiar (SCHIEDECK, 2015). No entanto, a taxonomia só tem relevância para quem vai seguir uma carreira científica. Para todos os demais, basta saber que é uma minhoca. Alguém usa no cotidiano a informação do que vem a ser um anelídeo?

Imagem 2: questão 82 da prova de química da 1a fase do vestibular Unicamp 2019

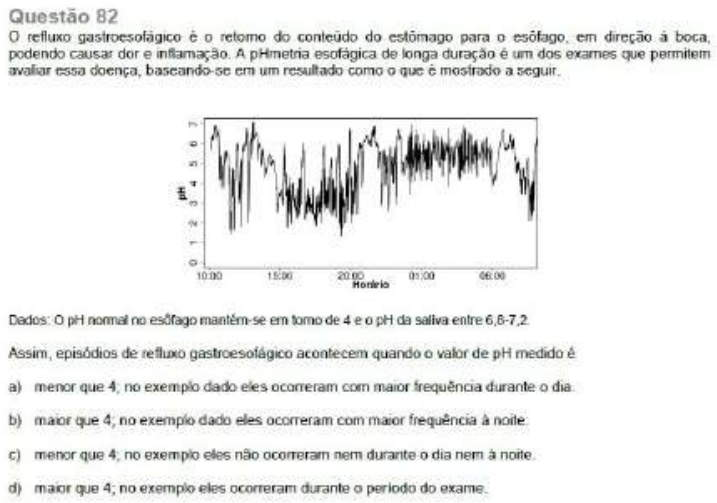

Fonte: Comvest (2019b)

Pode-se supor que alguns estudantes (e não todos) tenham contato, 
ao longo da vida, com alguma pessoa que tenha refluxo gastroesofágico, já que a incidência dessa doença no Brasil é de 12\% (HENRY, 2014). No entanto, a responsabilidade de leitura de um gráfico como o que é apresentado nessa questão é do médico que atende uma pessoa com essa doença e solicita esse exame.

A banca elaboradora da questão pode até supor que seria interessante o paciente entender o gráfico, caso o médico mostrasse a ele o resultado do exame. Mas qual seria o objetivo de possuir tal conhecimento? Não ser enganado por algum médico mal intencionado? Que razões um médico teria para dar uma informação falsa ao paciente em relação ao resultado do exame? Nesse caso específico, tal suposição parece, no mínimo, inverossímil.

No gráfico apresentado na questão, é possível perceber, visualmente, um predomínio de "registros" abaixo do ponto 4 de nível de $\mathrm{pH}$ no período do dia, mesmo sem linhas horizontais que pudessem facilitar essa leitura. No entanto, não há razão plausível para colocar diante de estudantes do ensino médio um gráfico com esse tipo de variação. A leitura de gráficos assim só será uma situação cotidiana para poucos.

Os Parâmetros Curriculares Nacionais do Ensino Médio (BRASIL, 2000) tratam da interpretação de gráficos com os quais os estudantes podem se deparar ao longo da vida, principalmente, através da mídia. Mas que tipo de gráfico é mais comum de se ver fora do meio científico ou da medicina? Um exemplo que seria mais significativo para os estudantes é o registro do crescimento de número de casos de uma doença como a dengue ao longo de um período de tempo específico como o verão.

Outro exemplo aparece em uma das questões do questionário do Indicador de Letramento Científico (INSTITUTO ABRAMUNDO, 2014), que apresenta dois gráficos, um com redução constante de bactérias ao longo de seis dias e outro com redução nos três primeiros dias e crescimento nos três dias seguintes, ambos sobre doentes infectados pela mesma bactéria e que tomaram antibióticos. O conhecimento esperado na questão é o efeito da interrupção do medicamento por um dos doentes antes do prazo prescrito pelo médico. Esse tipo de gráfico seria bem mais significativo para os estudantes. 
Imagem 3: questão 57 da prova de física da 1a fase do vestibular Unicamp 2019

\section{Questão 57}

O fisico inglés Stephen Hawking (1942-2018), além de suas contribuiçōes importantes para a cosmologia, a física teórica e sobre a origem do universo, nos últimos anos de sua vida passou a sugerir estratégias para salvar a raça humana de uma possível extinçăo, entre elas, a mudança para outro planeta. Em abril de 2018, uma empresa americana, em colaboração com a Nasa, lançou o satélite TESS, que analisará cerca de vinte mil planetas fora do sistema solar. Esses planetas orbitam estrelas situadas a menos de trezentos anos-luz da Terra, sendo que um ano-luz é a distância que a luz percorre no vácuo em um ano. Considere um ônibus espacial atual que viaja a uma velocidade média $v=2,0 \times 10^{4} \mathrm{~km} / \mathrm{s}$. O tempo que esse ónibus levaria para chegar a um planeta a uma distância de 100 anos-luz é igual a

(Dado: A velocidade da luz no vácuo é igual a $c=3,0 \times 10^{8} \mathrm{~m} / \mathrm{s}$.)
a) 66 anos.
b) 100 anos.
c) 600 anos.
d) 1500 anos.

Fonte: Comvest (2019c)

Embora a prova comentada (COMVEST, 2019c) não explicite a capacidade de encontrar atalhos de resolução entre os objetivos da questão, é plausível imaginar que a banca elaboradora pretendesse avaliar, entre outras coisas, se o estudante é capaz de perceber que o caminho mais fácil para realizar o cálculo do tempo que o ônibus espacial levaria para alcançar um planeta naquela distância da Terra é usar o mesmo tipo de grandeza na medida da velocidade. Ou seja, converter a velocidade da luz, que é apresentada em metros por segundo, para kilômetros por segundo, mesma grandeza usada para apresentar a velocidade do ônibus espacial; ou o inverso, converter a velocidade do ônibus espacial para metros por segundo.

A banca elaboradora da questão também explora a definição de ano-luz como unidade de distância. Porém, ao definir ano-luz como "a distância que a luz percorre no vácuo em um ano" e dizer que a velocidade da luz no vácuo é igual a certo número de metros por segundo, há margem para que alguns estudantes interpretem que seria preciso calcular quantos metros a luz percorreria em um minuto, uma hora, um dia, para então chegar ao seu percurso total em um ano. Embora tenha sido considerada pelos elaboradores uma questão fácil, de acordo com a prova comentada pela banca (COMVEST, $2019 c)$, menos da metade dos candidatos $(47,26 \%)$ soube que bastava multiplicar a velocidade da luz por 100 (anos-luz) e dividir o resultado pela velocidade do ônibus espacial. 
Qual seria a motivação dos elaboradores da questão? Seria difícil supor que a intenção fosse questionar a relevância do investimento de dinheiro público na exploração espacial, em virtude do enorme tempo que o ônibus espacial levaria para chegar a um planeta que orbita alguma estrela fora do sistema solar e, só então analisar se haveria condição de sobrevivência nesse planeta. Na velocidade com que a humanidade tem explorado os recursos naturais e degradado o meio ambiente desde a Revolução Industrial, não apenas os humanos como todas as outras formas de vida no planeta possivelmente não conseguiriam resistir a mil e quinhentos anos de espera.

Mas é improvável que seja esse tipo de questionamento que a banca elaboradora espera. O esperado é apenas saber fazer determinado tipo de cálculo. Com que finalidade? Após a realização da prova, a grande maioria dos estudantes não vai nunca mais precisar calcular algo parecido ao longo da vida. Um ensino médio voltado para esse tipo de conhecimento é uma formação fadada ao esquecimento.

\section{Questões em que o que é avaliado envolve escolhas como consumidor e cidadão}

Imagem 4: questão 24 da prova de biologia da 1ạ fase do vestibular Unicamp 2019

\footnotetext{
Questăo 24

O acidenle radioativo na usina de Chernobyl, na Ucrânia, em 1986, exigiu a evacuação de mais de 100 mil pessoas em um ralo de $30 \mathrm{~km}$. Até hoje, a reglăo é isolada e o aceseo público, restrito. Fouco tempo após o acidente, muitos eotudoe indicaram que vários organiemoe, entre os quaie aranhas e ineetos, haviam eofrido efeitos negativos da radiaçäo. Porém, estudos recentes, utilizando armadilhas fotooráficas e imagens aéreas, mostraram que a cidade-fantasma foi ocupada por diversas especies de plantas e animais, cuja abundância tem aumentado na regiäo.

(Deponivel em unw telegraph oo uk/newe/2018/04/23/wildlife-retums-to-radioa- ctive-wastaland-ot-chemobyl. Acessado on $15 / 03 / 2018$.)
}

\section{$1^{\text {a }}$ Fase $\cdot$ Ciências Biológicas}

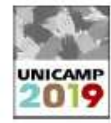

Aesinale a alternativa que fornece uma explicaçāo correta para o fenōmeno descrito no texto anterior.

a) A rađiação điminui a taxa fotossintética de piantas, porém a açăo de descontaminaçăo đo ambiente pelo homem permite o retorno de populaçōes de plantas e, portanto, doe organiemos que delas ee alimentam.

b) A raciaçäo aumenta a taxa de mutaçāo e acelera o metabolsmo de plantas, tavorecendo sua taxa reprodutiva, o que leva a aumento de auas populaçöes $e$, coneequentemente, dae populaçöes de herbivoros.

c) A radiaçāo reduz os tumoree de animais e plantas, aumentando a taxa de eobrevivēncia desceย ceree vivos c, consequentemente, o tamanho de suas populações e das de seus consumidores.

d) A radiaçäo tem impactoe negativoe sobre animaie e plantas, porem a aueència de afividade humana no ambiente contaminado por radiaçêo favorece o crescimento das populaçóes deases organiamoo.

Fonte: Comvest (2019a) 
Ainda que a banca elaboradora da prova de biologia não aponte essa como uma de suas três questões interdisciplinares, ela pode ser considerada interdisciplinar com química e física, já que aborda os efeitos negativos da radioatividade causada por um acidente em uma usina nuclear geradora de energia. E não é apenas o enunciado da questão que aborda um tema social, a evacuação da cidade de Chernobyl, na Ucrânia, decorrente de um acidente ligado a um avanço científico e tecnológico, a geração de energia em usinas nucleares. $O$ conhecimento esperado para o acerto da questão também envolve a reflexão sobre os impactos da atividade humana no ambiente.

Esse é um exemplo de tema que poderia ser abordado em aulas do ensino médio das disciplinas de biologia, química, física e também história e geografia, envolvendo debates sobre as consequências positivas e negativas da intervenção humana na natureza desde a descoberta do fogo, na pré-história, passando pelo surgimento da agricultura, quando os humanos deixaram de ser apenas coletores e caçadores, e pelo desenvolvimento da produção industrial até chegar aos mais recentes avanços da ciência e da tecnologia, tratando de seus impactos econômicos, geopolíticos, ambientais e sociais. Nessas aulas, poderiam ser abordadas as vantagens e desvantagens, os benefícios e os riscos da energia nuclear em comparação com as vantagens, desvantagens, benefícios e riscos de outras fontes de energia; outras aplicações de elementos radioativos, como na medicina, e outros exemplos de acidente, como o do Césio 137 em Goiânia.

As possibilidades de abordagem são inúmeras, todas elas com um potencial muito grande de mobilizar conhecimentos relevantes para a tomada de decisão dos estudantes como cidadãos, ao analisar os prós e contras de todas as opções apresentadas pelas políticas públicas para a composição da matriz energética do país e decidir o que apoiar ou não. Além disso, a reflexão sobre a capacidade de recuperação da biodiversidade em uma cidade-fantasma, sem os impactos da atividade humana, é de extrema relevância para a discussão sobre os limites do desenvolvimento científico e tecnológico e para uma urgente mudança de hábitos de consumo e de produção e distribuição de bens, com o objetivo de manter o bem maior, a vida no planeta. 
Imagem 5: questão 29 da prova de biologia da 1a fase do vestibular Unicamp 2019

\section{Questão 29 (Interdisciplinar com História)}

Raros são os cientistas que se dedicam a medir um único fenômeno. Mais raro ainda são aqueles que alteram o comportamento da humanidade com suas medições. O norte-americano Charles D. Keeling passou a vida medindo a quantidade de $\mathrm{CO}_{2}$ existente na atmosfera, demonstrando que a quantidade desse gás està aumentando. Em 1958, muito antes do surgimento dos movimentos ecológicos, Keeling desconfiou de que esse efeito era devido à queima de combustiveis fósseis. Na última década, a hipótese de Keeling foi testada pela análise de bolhas de ar retidas no gelo polar, revelando que a concentração de $\mathrm{CO}_{2}$ permaneceu inalterada por milênios, aumentando a partir do século XIX.

(Adaptado de Femando Reinach, A longa marcha đos gnllos canıbals. Săo Paulo: Compannıa das Letras, 2010, p. 41 42.)

Os experimentos com as bolhas de ar do gelo polar indicam que a elevação das emissões de $\mathrm{CO}_{2}$

a) é diretamente proporcional à utilização crescente de petróleo (plantas fossilizadas) nos Estados Unidos e na China no século XIX, o que propiciou o desenvolvimento de novos equipamentos, tecnologias e organizaçōes no mundo do trabalho.

b) está correlacionada com a utilização crescente de carvão mineral (plantas fossilizadas) durante a Revolução Industrial, que propiciou o uso da energia a vapor e o desenvolvimento de máquinas, levando à produção em larga escala.

c) está associada à utilização crescente de petróleo (micro-organismos fossilizados) desde os primórdios da Revolução Industrial, caracterizada pelo uso de máquinas para a produção em larga escala e novas organizaçőes trabalhistas

d) é diretamente proporcional à utilização decrescente de biodiesel (micro-organismos fossilizados) na Inglaterra durante a Revoluçāo Industrial, quando esse pais adotou uma matnz energètica baseada no consumo de petróleo para fomentar sua economia protecionista.

Fonte: Comvest (2019a)

Essa questão é apontada pela banca elaboradora da prova de biologia como sendo interdisciplinar com história. E, de fato, não se trata apenas de situar historicamente um conhecimento científico. Para resolver a questão, é preciso mobilizar um conhecimento de história, o uso de carvão mineral para gerar energia a vapor e movimentar máquinas durante a Revolução Industrial, e associá-lo à mudança ocorrida no gelo polar a partir do século XIX. Esse tema também possibilita abordagens interdisciplinares com a química e o estudo da combustão, com a física e o estudo da termodinâmica, com a geografia e o estudo da exploração econômica de recursos naturais e das regiões exportadoras e importadoras de matérias-primas e das regiões mais industrializadas e menos industrializadas.

O mais importante é que tanto o enunciado quanto o conhecimento cobrado para resolver a questão envolvem temas extremamente ricos em seu potencial para discussões em sala de aula do ensino médio envolvendo tomadas de decisão dos estudantes como consumidores e cidadãos. $\mathrm{O}$ tema das mudanças climáticas e do aquecimento global decorrente da queima de 
combustíveis fósseis é de crucial importância na atualidade e envolve o posicionamento do cidadão não apenas diante de políticas públicas que coloquem limites nas emissões de gases do efeito estufa, mas também em seu comportamento como consumidor, na escolha do combustível que irá colocar em seu carro ou do tipo de transporte que usará preferencialmente, se individual ou coletivo, se exigirá do poder público mais ciclovias que possam ser usadas para ir à universidade ou ao trabalho, como a que há no distrito de Barão Geraldo, em Campinas, onde se situa a Unicamp.

\section{Considerações finais}

A análise apresentada aqui revela que parte das questões das provas de ciências da natureza do vestibular da Unicamp apenas ilustra o conhecimento avaliado com algum tema da vida cotidiana apresentado no enunciado; outra parte tem potencial para discussões envolvendo tomada de decisão, porém, o conhecimento cobrado não influi no processo de exercício de cidadania e tem relevância apenas para os futuros cientistas; e, por fim, são raras as questões em que tanto o enunciado quanto aquilo que é avaliado envolvem conhecimento que todos os estudantes, e não apenas os futuros cientistas, usarão para tomar decisões como cidadãos.

Aikenhead (1994), ao analisar iniciativas de reformas no ensino de ciências em diversos países, influenciadas por contribuições das pesquisas sobre ensino CTS, apresenta oito diferentes níveis de inserção desse tipo de abordagem no conteúdo geral das disciplinas de ciências, desde a mera menção de conteúdo CTS como motivação para tornar a lição mais interessante até um ensino totalmente voltado para temas sociais com algum componente científico.

Como o vestibular da Unicamp é realizado em duas fases, com um corte de dezenas de milhares de candidatos de uma fase para a outra, seria razoável se as provas de biologia, química e física da primeira fase apresentassem questões totalmente voltadas para temas sociais com algum componente científico ou tecnológico, já que o público dessa fase é bem mais amplo que o da segunda, na qual, as questões poderiam ser mais voltadas para avaliar a base de conhecimento daqueles que escolheram seguir uma carreira científica. Esse balanço na distribuição temática das provas das duas fases certamente teria um impacto significativo no ensino médio e é bem provável que as contribuições das pesquisas em ensino de ciências já incorporadas pelos Parâmetros Curriculares, enfim, chegassem de fato às salas de aula. 


\section{Referências}

AIKENHEAD, G. What is STS Science Teaching? In: SOLOMON, J; AIKENHEAD, G. (Org.). STS education: international perspectives on reform. New York: Teachers College Press, 1994.

BRASIL. Parâmetros Curriculares Nacionais do Ensino Médio. Brasília (DF): MEC/SEF, 2000.

COMVEST - Comissão Permanente para os Vestibulares. Prova comentada de ciências biológicas, vestibular Unicamp 2019 1ạ fase, Campinas, 2019a. 20 páginas. Disponível em https://www2.comvest.unicamp.br/vestibulares-anteriores/. Acesso em: 09/03/2020.

COMVEST - Comissão Permanente para os Vestibulares. Prova comentada de química, vestibular Unicamp 2019 1a fase, Campinas, 2019b. 21 páginas. Disponível em https://www2.comvest.unicamp.br/vestibulares-anteriores/. Acesso em: 09/03/2020.

COMVEST - Comissão Permanente para os Vestibulares. Prova comentada de física, vestibular Unicamp 2019 1a fase, Campinas, 2019c. 16 páginas. Disponível em https://www2.comvest.unicamp.br/vestibulares-anteriores/. Acesso em: 09/03/2020.

CUNHA, Rodrigo Bastos. A centralidade da linguagem nos trabalhos sobre letramento científico. In: Anais da 71ㅁ Reunião Anual da SBPC. UFMS, Campo Grande, 2019.

GOMES, Rafaela Sampaio; MACEDO, Simone da Hora. Cálculo estequiométrico: o terror das aulas de Química. Vértices, v. 9, n.1/3, jan./dez. 2007, p. 149-160.

HENRY, Maria Aparecida Coelho de Arruda. Diagnóstico e tratamento da doença do refluxo gastroesofágico. Arquivo Brasileiro de Cirurgia Digestiva, v. 27 , n.3, 2014, p. 210-215.

HURD, Paul. Science literacy: Its meaning for American schools. Educational Leadership, v. 16, n. 1, October 1958, p.13-16 (continua na página 52).

INSTITUTO ABRAMUNDO. ILC - Indicador de Letramento Científico: Sumário executivo de resultados, 2014. Disponível em http://iblc.org.br/. Acesso em: 13/03/2020.

MOETO, Cecília Borges; PEREIRA, Isabela Lopes; MENEZES, Paulo Henrique Dias. A influência dos processos seletivos das universidades sobre os currí- 
culos de física da escola básica: estudo comparativo entre questões de física do ENEM e de um programa de ingresso em universidade pública. In: Atas do XI Encontro Nacional de Pesquisa em Educação em Ciências (ENPEC). UFSC, Florianópolis, 2017.

ROBERTS, Douglas. Scientific literacy. Towards a balance for setting goals for school science programs. Ottawa, ON, Canada: Minister of Supply and Services, 1983.

ROBERTS, Douglas. Scientific Literacy/Science Literacy. In: ABELL, S. K.; LEDERMAN, N. G. (Org.). Handbook of Research on Science Education. New York: Routledge, 2007.

RODRIGUES, Clarissa. Abordagem CTS e Possibilidades de Letramento Científico no Projeto Água em Foco: Tipos Textuais e Linguagem Científica. 2010. 99f. Dissertação (Mestrado em Educação). Programa de Pós-graduação em Educação da Faculdade de Educação. Universidade Federal de Minas Gerais. Belo Horizonte: UFMG, 2010.

RODRIGUES, Victor Augusto Bianchetti; QUADROS, Ana Luiza. O ensino de ciências a partir de temas com relevância social contribui para o desenvolvimento do letramento científico dos estudantes? Revista Electrónica de Enseñanza de las Ciencias, v. 19, n. 1, 2019, p. 1-25.

SANTOS, Wildson Luiz Pereira dos. Aspectos sócio-científicos em aulas de química. 2002. 336f. Tese (Doutorado em Educação). Programa de Pós-graduação em Educação da Faculdade de Educação. Universidade Federal de Minas Gerais. Belo Horizonte: UFMG, 2002.

SCHNETZLER, Roseli Pacheco; SANTOS, Wildson Luiz Pereira dos. Educação em química: compromisso com a cidadania. Ijuí: Ed. Unijui, 1997.

SCHIEDECK, Gustavo. A minhocultura na agricultura familiar - Estratégia de apoio para a transição agroecológica. In: ANJOS, J. L. dos; AQUINO, A. M. de; SCHIEDECK, G. (Org.). Minhocultura e vermicompostagem: interface com sistemas de produção, meio ambiente e agricultura de base familiar. Brasília: Embrapa, 2015.

SCHIEDECK, Gustavo; SCHWENGBER, José Ernani; CARDOSO, Joel Henrique; GONÇALVES, Márcio de Medeiros; SCHIAVON, Greice de Almeida. Aspectos culturais associados às minhocas no Brasil. Acta Zoológica Mexicana, v. 26, número especial 2, 2010, p. 19-33.

SOUSA, Bárbara Lethicya Silva; BEZERRA, Cícero Wellington Brito; SILVA, Jackson Ronie; CATANHEDE, Severina Coelho da Silva; CATANHEDE, Leonardo 
Baltazar. Cenário das publicações CTS/CTSA no ensino de química: revisão bibliográfica de publicações no portal de periódicos da CAPES/CAFÉ. Brazilian Journal of Development, v. 5, n. 11, nov. 2019, p. 27267-27283.

Data de recebimento: 11.06 .2020

Data de aceite: 06.05.2021 